\title{
An opinion paper: Strengthening the weakest link in food safety
}

\author{
Shawna Bourne BASc \\ In cooperation with the Stanier Institute/Institut Stanier
}

\section{THE PUBLIC HEALTH INSPECTOR PERSPECTIVE}

In today's global arena the last line of defense in food safety is always the consumer. An educated and resourceful client has the ability to compensate for any weak links in the food safety chain. The role of effectively disseminating information on food safety falls into the domain of the public health inspector (PHI), within the local health unit. However, this responsibility is often overlooked because PHIs and other government regulators seek to make producers, suppliers and retailers more responsible for the quality and safety of the food that we, as Canadians, enjoy and take for granted. The mandate of the Canadian Institute of Public Health Inspectors (CIPHI) is to "...protect the health of all Canadians on environmental issues while promoting the science of environmental health and the profession" (1). We meet this mandate through education and the enforcement of food safety standards. Environmental Health Officials also undertake the challenge of ensuring accountability from primary producer to processor. This dual role of educator and enforcer is a difficult act to balance, yet important to achieve our goal of optimal food safety.

Information describing the extent of food safety problems is limited. The best current information for health professionals, planners, and public health agencies responsible and accountable for local food safety is the estimate that 2.2 million Canadians suffer from food borne illnesses each year (2), but these data are very incomplete. The Canadian Institute for Health Information (CIHI) annual report (3) noted a fundamental information gap in public health exists in the area of food and water safety. We don't know "how many Canadians become ill each year because of unsafe food or water [and] what are the short- and long-term health consequences of their illness?" (3). Dr Douglas Powell (4) of the University of Guelph notes:

Best estimates based on active surveillance in the U.S. have found that up to one in four Americans each year are sickened from the food and water they consume. Comparable Canadian numbers would mean approximately 7 million people contracted food or waterborne illness each year.

This is a much larger number than reported by Health Canada. In fact, the estimate that 2.2 million Canadians suffer from gastroenteritis each year is based on the supposition that as few as
$10 \%$ of all cases are actually reported (5). Why are estimates still used when food borne illness statistics should be so readily quantifiable?

There are a number of factors limiting the generation of complete and accurate information. First, when the average person becomes ill with gastroenteritis they often continue daily activities in spite of symptoms, or remain at home for a short period of $24 \mathrm{~h}$ to $48 \mathrm{~h}$ waiting for the nausea, diarrhea and stomach cramps to subside. Only more serious complications such as dehydration, bloody diarrhea, jaundice or prolonged illness will lead the sick to seek medical attention. In addition, continuing normal activities while ill may lead to further transmission - one individual with food borne illness may be a source for multiple secondary cases at home or work. The second factor affecting accurate benchmarking and trending of disease occurrence is limited specimen collection from cases. When the patient does present to an ambulatory clinic with potential food borne illness, a clinical diagnosis alone is frequently made, without microbiological confirmation. Physicians and other health care providers often do not notify the health department to initiate further investigation when a clinical case is diagnosed. Third, on the few occasions when patient self-reporting occurs and suspect food is available for testing, obtaining stool samples from the affected individual in a timely fashion is a challenge. Without microbiological documentation, establishing a causal link between inconsistencies in environmental health practices and disease is often not possible. This also increases the complexity of the investigation and limits identification of the source.

To improve disease reporting and microbiological documentation of the etiological agent, PHIs must educate the public and the health care workers who interact with people suffering from food borne illness with respect to these oversights. Professionals in health care should be trained to follow consistent best practices, including standardized reporting across Canada. Educational campaigns and programs must be developed to include health care professionals working in health units, hospital emergency departments, walk-in clinics, pharmacies and other locations. A social marketing campaign should target the general public who are likely to suffer from food borne illnesses. The goal is to raise awareness about appropriate responses to a potential food or waterborne illness event. A model for such a public outreach and educational initiative is the Fight Bac! Campaign (6). This was initiated as a 
partnership of stakeholders concerned about food safety with the goal of reducing microbial food borne illness in Canada. This goal is to be achieved by increasing awareness of safe food handling practices through the comprehensive delivery of consumer-focused food safety education programs (6).

To supplement the current Fight Bac! Campaign, which targets the consumer in its food safety objectives, a clear set of objectives and a process for their implementation must be identified. Setting standards for case finding and clinical guidelines to support appropriate stool sample collection is needed, including when and how referrals to the environmental health division of the health unit are appropriate. An equally important message would instruct the public on appropriate medical attention when a food borne illness is suspected, and on how to ensure that patients and their caregivers receive necessary care and instruction to prevent transmission. This will require collaboration between public and clinical health care providers. Such an educational campaign should build upon the Fight Bac! message of food safety, clearly and concisely addressing gaps in the reporting and monitoring of food borne illness. The communication should be directed to both healthcare professionals and the public. It should include information about the signs and symptoms of food borne illness; what an individual with potential signs of illness related to food borne disease should do; and who to contact at the onset of disease symptoms. The final important element will be to convey what information is relevant and why (eg, period of communicability, possible sources, how to prevent spread, etc). An effective social marketing campaign will address all of these issues in a manner that resonates with both the general public and health professionals.

To heighten awareness we need more accurate data of illness in our society. This includes baseline statistics of incidence and a means to assess the continuing impact of food borne illness. This can be achieved initially through a cross-sectional survey of the general population to provide a more complete overview of the impact of food borne illness on the health of society. Data collected in such a survey should include the number of individuals who believe they have suffered from a food borne illness in the past 12 months, the number of separate episodes of diarrhea, vomiting and stomach cramps experienced, and whether medical attention was sought. This baseline information will be a foundation for future prospective surveillance activity, useful for planning the scope of future educational and practice endeavors, and will indicate the urgency with which these interventions should be implemented.

Social marketing to the public through health promotion and education techniques are tools that are not always used by PHIs in relation to the community at large. But we 'market' this expertise for restaurateurs, hospital administrators and other operators in the field. These skills, which are so useful on the job, can also be used to encourage the public to adopt better food safety practices, and promote collaboration between clinical and public health professionals; developing a strong partnership to increase food safety awareness in the community. Human and financial resources are needed to enhance these 'inherent' professional, persuasive skills. This will allow for the production of materials targeting various groups with the goal of improving the interdisciplinary cohesion between our profession and others.

The time is ripe - food safety is a hot topic and we must use this to our advantage and for the well-being of the public. An informed consumer is an empowered and safer citizen. We must encourage the general public to become knowledgeable advocates for their own personal health.

\section{REFERENCES}

1. Canadian Institute of Public Health Inspectors. CIPHI Exists to Certify, Inform and Advocate. <http://www.ciphi.ca/> (Version current at April 14, 2003).

2. Health Canada. Budget 1999: Food Safety and Nutrition. $<$ http://www.hc-sc.gc.ca/english/budget/1999/factsht8.htm> (Version current at April 14, 2003).

3. Canadian Institute for Health Information. Health Care In Canada: 2002. Ottawa: Canadian Institute for Health Information, 2002.

4. Powell D. Slim Evidence to Date Suggests Little Difference in Risk Between Organic vs Conventional. Canada: Ontario Farmer, 2003.

5. Information, Analysis, and Connectivity Branch, Health Canada. Departmental Performance Report 2000-2001, Annex A: Measuring Health in Canada. Ottawa: Health Canada, 2001.

6. Canadian Partnership for Consumer Food Safety Education. Business Plan 2000-2001 and Beyond. Ottawa: Canadian Partnership for Consumer Food Safety Education, 2001. 


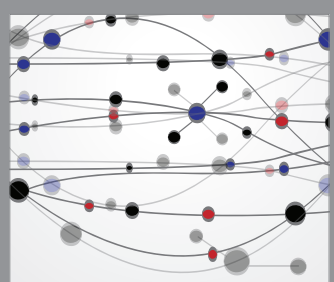

The Scientific World Journal
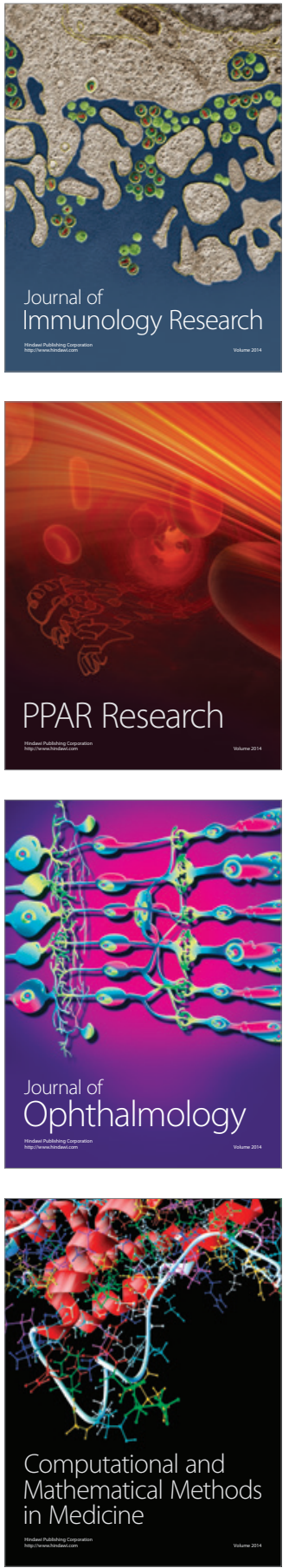

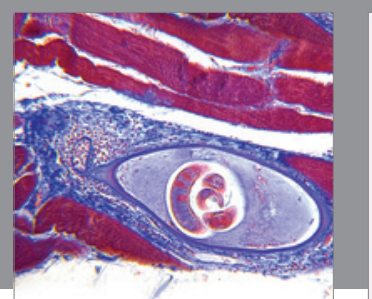

Gastroenterology Research and Practice

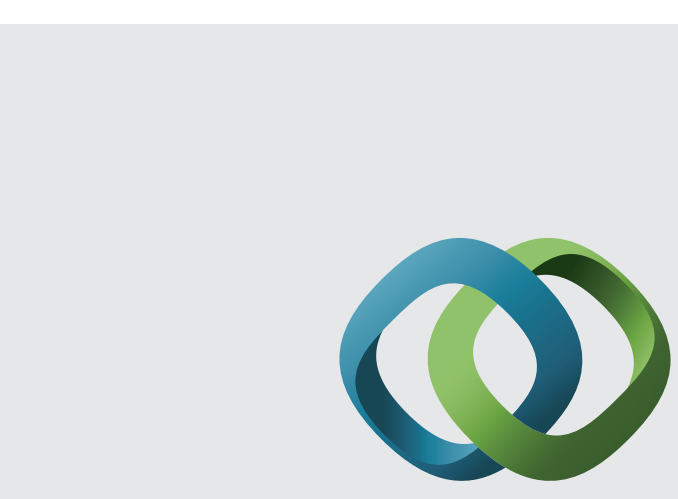

\section{Hindawi}

Submit your manuscripts at

http://www.hindawi.com
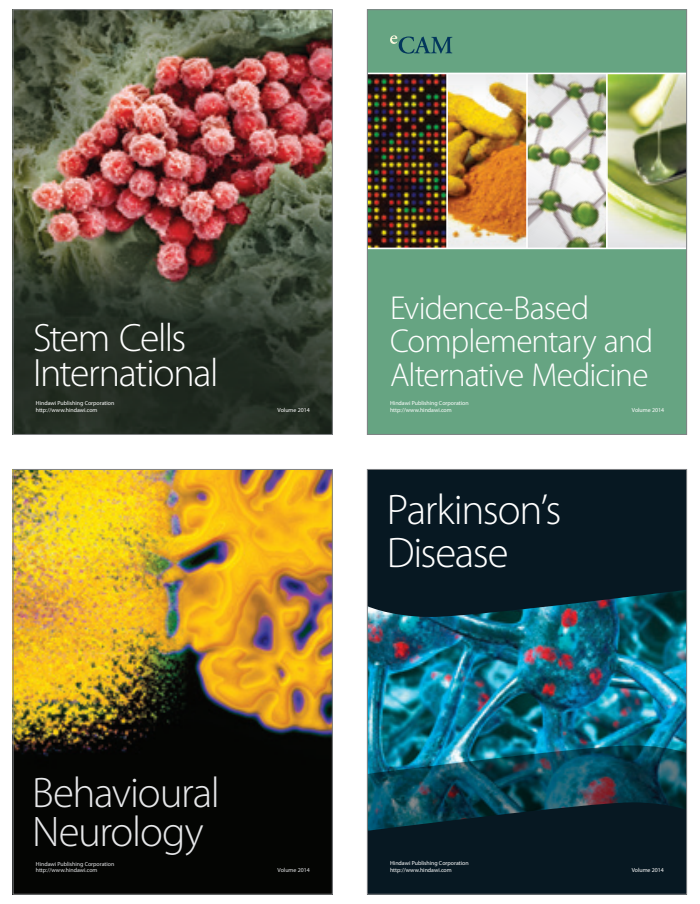
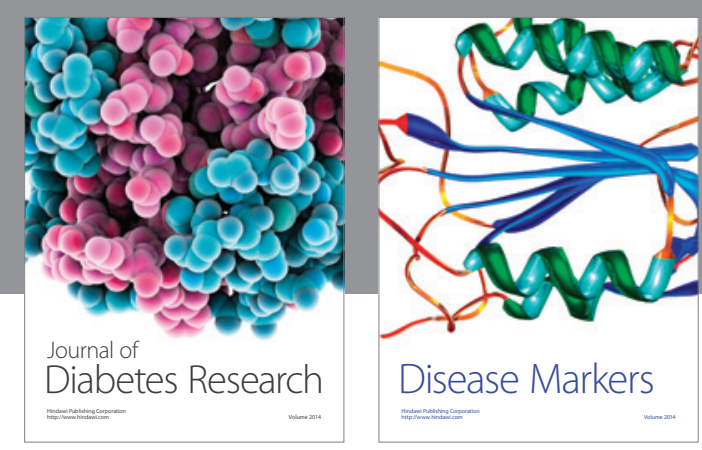

Disease Markers
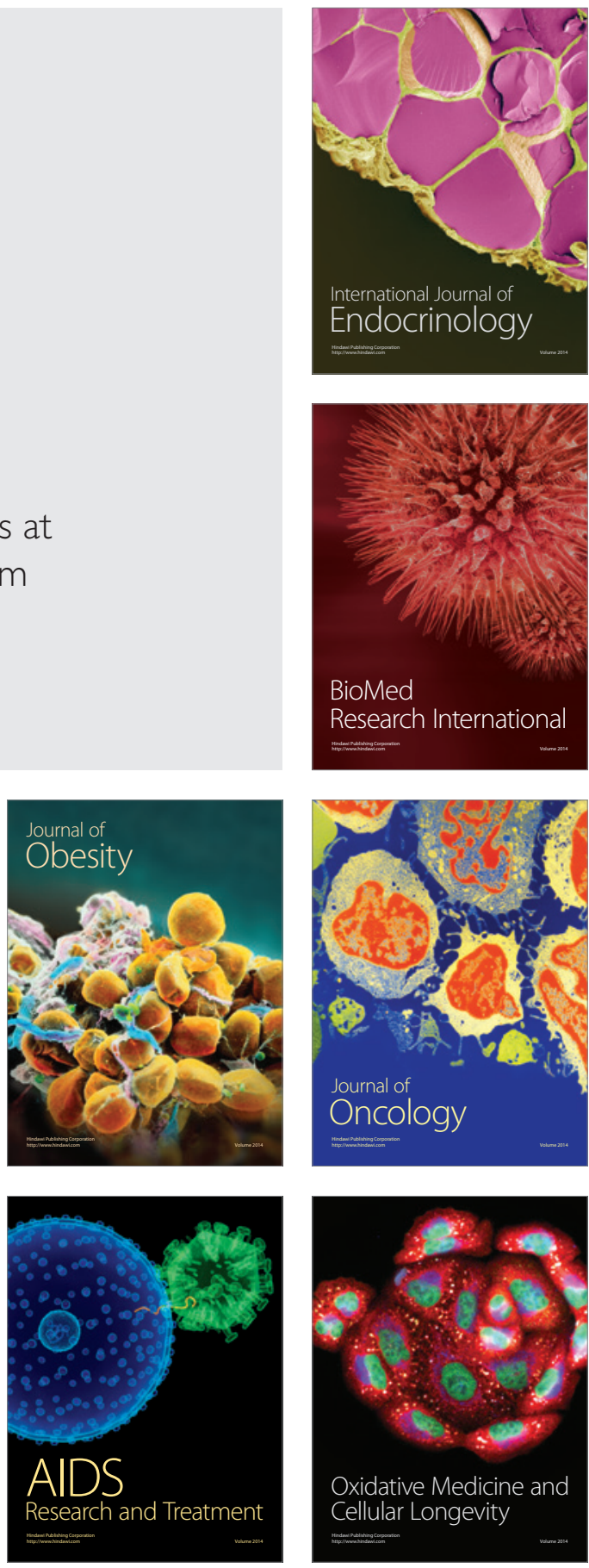